\title{
Coral biodiversity and bio-construction in the northern sector of the mesoamerican reef system
}

\author{
Fabián A. Rodríguez-Zaragoza ${ }^{1}$ and Jesús E. Arias-González ${ }^{2 *}$ \\ ' Laboratorio de Ecosistemas Marinos y Acuicultura, Departamento de Ecología, Centro Universitario de Ciencias Biológicas y Agropecuarias, Universidad de \\ Guadalajara, Jalisco, México \\ 2 Laboratorio de Ecología de Ecosistemas de Arrecifes Coralinos, Departamento de Recursos del Mar, Centro de Investigación y de Estudios Avanzados del IPN, \\ Unidad Mérida, Yucatán, México
}

\section{Edited by:}

Hajime Kayanne, The University of

Tokyo, Japan

\section{Reviewed by:}

Juan Pablo Carricart-Ganivet, Universidad Nacional Autónoma de México, Mexico

Nyawira A. Muthiga, Wildlife Conservation Society, Kenya

\section{*Correspondence:}

Jesús E. Arias-González, Laboratorio de Ecología de Ecosistemas de Arrecifes Coralinos Departamento de Recursos del Mar, Centro de Investigación y de Estudios Avanzados del IPN, Antigua Carretera a Progreso Km 6, Mérida, Yucatán C.P. 97310, México e-mail: earias@mda.cinvestav.mx; jeariasg@mac.com
As the impact of anthropogenic activity and climate change continue to accelerate rates of degradation on Caribbean coral reefs, conservation and restoration faces greater challenges. At this stage, it is of particular importance in coral reefs to recognize and to understand the structural spatial patterns of benthic assemblages. We developed a field-based framework of a Caribbean reefscape benthic structure by using hermatypic corals as an indicator group of global biodiversity and bio-construction patterns in 11 reefs of the northern sector of the mesoamerican barrier reef system (nsMBRS). Four hundred and seventy four video-transects $(50 \mathrm{~m}$ long by $0.4 \mathrm{~m}$ wide) were performed throughout a gradient of reef complexity from north to south $(\sim 400 \mathrm{~km})$ to identify coral species, families and ensembles of corals. Composition and abundance of species, families and ensembles showed differences among reefs. In the northern zone, the reefs had shallow, partial reef developments with low diversities, dominated by Acropora palmata, Siderastrea spp., Pseudodiploria strigosa, and Agaricia tenuifolia. In the central and southern zones, reefs presented extensive developments, high habitat heterogeneity, and the greatest diversity and dominance of Orbicella annularis and Orbicella faveolata. These two species determined the structure and diversity of corals in the central and southern zones of the nsMBRS and their bio-construction in these zones is unique in the Caribbean. Their abundance and distribution depended on the reef habitat area, topographic complexity and species richness. Orbicella species complex were crucial for maintaining the biodiversity and bio-construction of the central and southern zones while A. palmata in the northern zones of the nsMBRS.

Keywords: coral reefs, coral assemblages, biodiversity, bio-construction, mesoamerican barrier reef system

\section{INTRODUCTION}

Compared to other marine ecosystems, coral reefs possess the greatest taxonomic and functional diversity of the planet, due to the structural complexity of their habitats, which generate multiple ecological niches for thousands of associated species (Jackson et al., 2001). This biodiversity favors reef stability and provides benefits for people, including alimentary and economic resources such as tourism, fisheries and coastal protection (Bellwood et al., 2004).

Worldwide, reefs of the Western Atlantic present an intermediate to low biodiversity due to biogeographical and geological processes (Veron, 1995). This biodiversity has decreased because of human and natural disturbances that have lead to phase shifts from coral dominance to macroalgal dominance (Gardner et al., 2003; Pandolfi et al., 2003; Mora, 2008). Within the Western Atlantic, the reefs of the northern sector of the nsMBRS are under chronic stress from human activities and natural disturbances such as hurricanes and massive tourism (Núñez-Lara et al., 2005; Bozec et al., 2008; Healthy Reefs, 2012). This is reflected in the low coral covers and moderate to high macroalgae covers, coral mortalities and frequent diseases, as well as low densities of carnivores and herbivores (Kramer, 2003; Bozec et al., 2008). Nevertheless, in the year 2000 the reefs of the nsMBRS still presented extensive areas of relatively conserved live coral, due to their status as marine protected areas such as the Sian Ka'an Biosphere Reserve or the presence of small human settlements. However, in the northern zone, reefs are considerably degraded by coastal urban development and the effects of tourist and fishing activities (Núñez-Lara et al., 2005; Bozec et al., 2008; Healthy Reefs, 2012). Furthermore, the ecological studies in this sector have increased in recent decades, particularly, in the community structure of different biological assemblages (e.g. NúñezLara et al., 2005; Reyes-Bonilla et al., 2014), the contribution of alpha, beta and gamma diversity of reef fish (Arias-González et al., 2008; Rodríguez-Zaragoza and Arias-González, 2008), key ecological drivers (Arias-González et al., 2011), the effects of biodiversity loss (Acosta-González et al., 2013), reef architectural complexity assessments (Alvarez-Filip et al., 2011), and trophic functioning (e.g., Arias-González et al., 2004; Alva-Basurto and Arias-González, 2014). 
To find out the condition of the reefs and conserve their biological richness and current physical characteristics, it is necessary to perform evaluations of the biodiversity of key groups (Done et al., 1996). These evaluations are fundamental to elucidate how biodiversity influences the functioning of ecosystems, given that this confers a high degree of functional redundancy, where the loss of a species is potentially compensated by the action of another (Bellwood et al., 2004) or to identify the vulnerability of species assemblages and to restore it. For this evaluation, the use of biodiversity indicator groups has been proposed (Pearson, 1995). Corals have been proved to be one of the essential groups for understanding resilience and avoiding phase shifts (Bellwood et al., 2004). Corals are the main coral reef building organisms by their continuous accumulation of carbonates, and functionality, since the shape of the colonies reflects their function in the reef process, which includes the creation of three dimensional habitats for fish and other organisms (Bellwood et al., 2004). In this way, corals are ecosystem engineers that influence the global species richness of the reefs, giving specific resources such as substrate, refuges, and food for a multiplicity of species.

To perform evaluations of biodiversity it is important to analyze the ecological diversity of the indicator group studied, which takes into account the species richness, composition, abundance and evenness, in different taxonomic hierarchies, and functional groups, - named here as ensembles. This implies the study of the different ecological sets of organisms (communities, assemblages and ensembles) defined by geography, resources, and phylogeny (Fauth et al., 1996). The assemblages are taxonomically related species of a community, and the ensembles are members of an assemblage that exploit a common resource (Fauth et al., 1996).

In this study, the evaluation of the coral diversity was based on the structure of coral assemblages at species, family, and ensemble level. Hermatypic corals were considered as an indicator group of the biodiversity and bio-construction of the coral reefs. We examinated the biodiversity with the analysis of the structure and diversity of the coral assemblages in 11 fringing reefs of the nsMBRS in order to establish which are the biological variables that influence the structure and diversity of corals, and to identify the reefs that potentially present greater biodiversity and bio-construction in this region. This information is relevant for finding out the ecological dynamics of the corals on the biodiversity and reef development; it is equally fundamental for the management and conservation of the coral reefs of the MBRS.

\section{MATERIALS AND METHODS STUDY AREA}

The reefs of the nsMBRS form a semi continuous barrier that extends from Cancun $\left(21^{\circ} 00^{\prime} \mathrm{N}, 86^{\circ} 46^{\prime}\right)$ to the border between Mexico and Belize $\left(18^{\circ} 16^{\prime} \mathrm{N}, 87^{\circ} 49^{\prime} \mathrm{O}\right)$. The eleven reefs analyzed in this study are located in three zones delimited by their geomorphological characteristics and anthropogenic use (NúñezLara et al., 2005) (Figure 1): Punta Nizuc, Puerto Morelos, and Punta Maroma in the northern zone; Boca Paila, Yuyum, Punta Allen and Tampalam in the central zone; and El Placer, Mahahual, Xahuayxol, and Xcalak in the southern zone. The reef development increases along a north-south gradient. The reefs of the northern zone possess two habitats, lagoon and front, with shallow, discontinuous coral formations, separated by large expansions of sand. The reefs of the central and southern zones have four habitats, lagoon, front, slope and terrace, and are more developed, with spur and groove systems. The physical characteristics of the reefs studied have been described by RuízZárate and Arias-González (2004) and Núñez-Lara et al. (2005). Protected marine areas also exist such as National Parks in Punta Nizuc, Puerto Morelos, Xahuayxol and Xcalak, and the Biosphere Reserve, which includes all the sites of the central zone.

\section{SAMPLING AND DATA COLLECTION}

A total of 474 videotransects ( $50 \mathrm{~m}$ long and $0.4 \mathrm{~m}$ wide) obtained between June and September 1999 and 2000 were analyzed (Núñez-Lara et al., 2005). In 1999 the reef fronts and terraces were sampled $(\sim 6$ and $\sim 20 \mathrm{~m}$ deep) and in 2000 the lagoons and slopes $(\sim 3$ and $\sim 10 \mathrm{~m}$ deep $)$. The sampling effort per reef varied between 28 and 58 videotransects. A total of 40 frames were reviewed, with 13 fixed points systematically distributed per videotransect, to record the richness and cover of coral species. The coral cover was calculated per reef at species, family and ensemble level. The coral ensembles were established based on the shape of the coral colonies: semispherical, brain, boulder, leafy-encrusting, column, branching, finger, flower-cup, and fleshy.

A number of environmental variables that potentially influence the structure and diversity of the coral assemblages were analyzed: (1) total live coral cover, algae (including fleshy macroalgae, calcareous algae, turf and others), sand and calcareous substrate (calcareous rock and dead coral), which were estimated from the videotransects; (2) reef habitat area, estimated with Landsat TM images and supervised images in the ERDAS 8.7 program (ERDAS Inc.); and (3) topographical complexity index quantified with the chain method and calculated by the flowing equation (Aronson et al., 1994):

$$
C T=1-D / L
$$

where topographic complexity is the habitat complexity, $D$ is the horizontal distance of the chain following the profile of the substrate and $L$ is the total length $(18 \mathrm{~m})$.

\section{ECOLOGICAL ANALYSIS}

The sampling effort was evaluated with accumulated curves from the Shannon Wiener $\left(\mathrm{H}^{\prime}\right)$ index using the EstimateS V7.5 program (Colwell, 2005). The curves showed an asymptotic tendency, indicating an adequate representation of the coral species, and validated the comparisons among reefs (Supplementary Figure S1).

The structure (composition and abundance) of the coral assemblages, families and ensembles was compared among reefs with a one-way similarities analysis (ANOSIM), based on data transformed with the square root, Bray-Curtis similarity matrices and 9999 permutations. The contributions of the species, families and ensembles per reef were estimated with a percentages similarity analysis (SIMPER) (Clarke and Warwick, 1994). Both methods were run in the PRIMER 5.2 program (Plymouth Marine Lab. UK). 


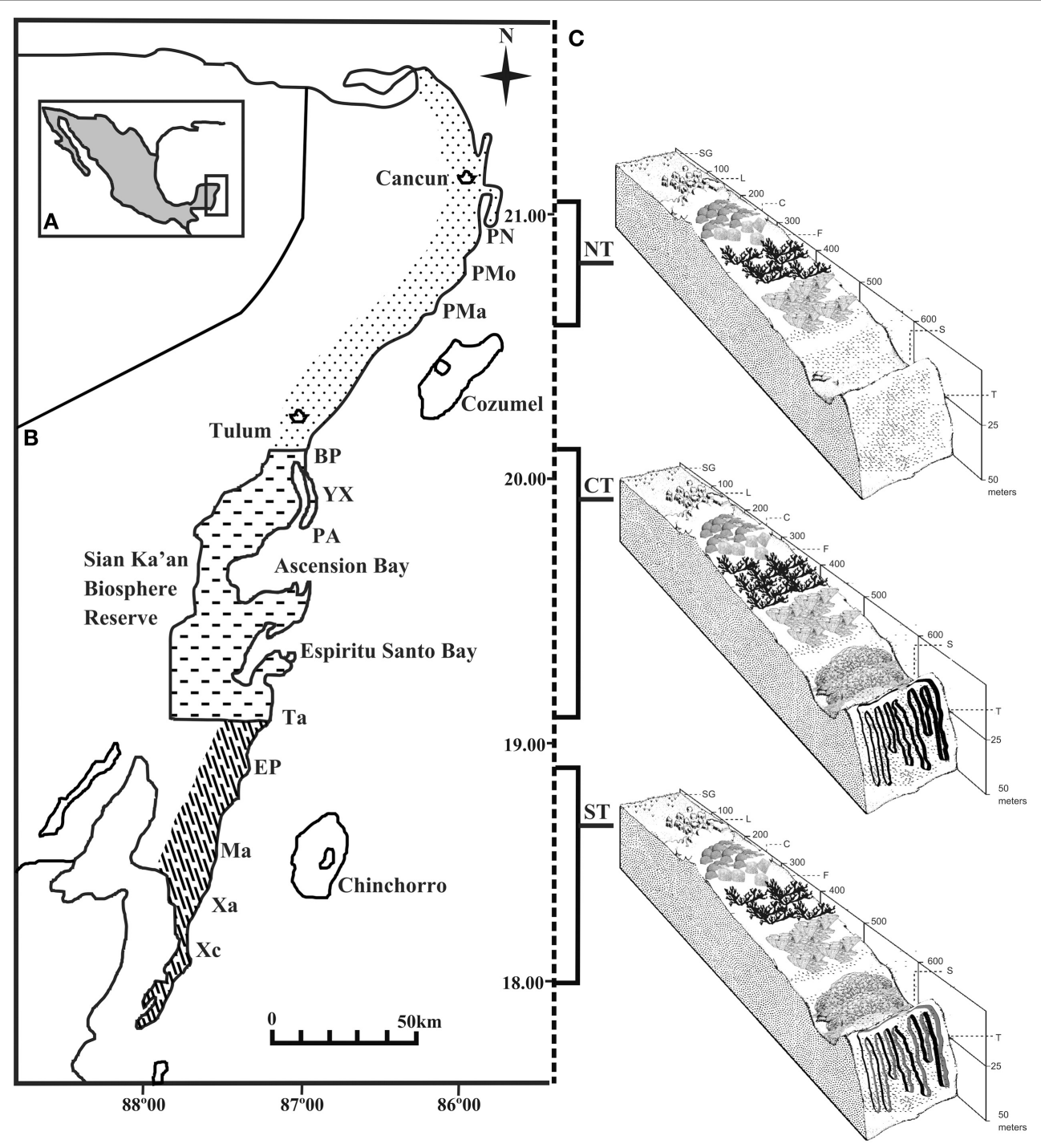

FIGURE 1 | Study area. (A) Yucatan Penisula. (B) Mexican Caribbean coast, with three regions. Eleven reef sites along the coast were selected for the study: Punta Nizuc (PN), Puerto Morelos (PMo), Punta Maroma (PMa), Boca Paila (BP), Yuyum (YX), Punta Allen (PA), Tampalam (Ta), El Placer (EP), Mahahual (Ma), Xahuayxol (Xa) and Xcalak (Xc). (C)
Suggested division of the Mexican Caribbean reefs according to geomorphology: Northern zone (NT), Central zone (CT), and Southern zone (ST). Typical habitats of reef geomorphology in the fringing reef system are illustrated: lagoon (L), crest $(C)$, front $(F)$, slope $(S)$ and terrace (T). Depths in meters.
Coral diversity was analyzed with Hill's numbers series:

$$
\begin{aligned}
N_{0} & =S \\
N_{1} & =e^{H^{\prime}} \\
N_{2} & =1 / D \\
N_{b} & =N_{0}-\left(N_{1}+N_{2}\right) \\
N_{21} & =N_{2} / N_{1}
\end{aligned}
$$

where $N_{0}$ and $S$ are the organism richness or the number of coral species, families and ensembles, $N_{1}$ is the number of species, families and ensembles with medium abundance, $H^{\prime}$ is the Shannon diversity index $\left(H^{\prime}=-\sum_{i=1}^{S} p_{i} \ln p_{i}\right.$, where $p_{i}$ is the abundance, proportional to the species $i), N_{b}$ is the number of species, families or ensembles with low abundance, $N_{2}$ is the number of species, families and ensembles with high abundance, $D$ is Simpson's dominance index, $\left(D=\sum_{i=1}^{S} p_{i}^{2}\right)$, and $N_{21}$ is Hill's evenness (Hill, 1973).

The diversity of coral species, families and ensembles was analyzed with a non-metric multidimensional scaling analysis (NMDS) and a cluster analysis (CA) using UPGMA linking method. The similarity matrices were constructed using Hill's numbers, previously transformed with the square root and the Bray-Curtis coefficient in the PRIMER 5.2 program (Plymouth Marine Lab. UK).

The reef bio-construction was estimated based on the following equation: 


$$
A A=\sum_{i=1}^{n} C_{i} \cdot A E A \cdot C L_{i}
$$

where $A A$ is an approximation of the reef accretion in $\mathrm{cm}^{-3}$, subsequently converted into $\mathrm{m}^{-3}$; $C$ is the live cover of the species $i$ expressed as a ratio; AEA is the area of the reef structure in $\mathrm{cm}^{-2}$; $C L$ is the lineal growth rate of the species $i$ in $\mathrm{cm}_{\text {year }}{ }^{-1}$, obtained from published literature (Bak and Meesters, 1997; Carricart-Ganivet, 2004; García-Urueña, 2004; Duran, 2006). AA was estimated with the species that contributed to $95 \%$ of the total contribution calculated with the SIMPER per reef.

The environmental variables among reefs were compared with unrestricted statistics because they did not meet the parametric assumptions. Kruskal-Wallis $(\mathrm{H})$ tests were used for the live coral cover and the covers of algae, sand, calcareous substrate and habitat complexity. The Chi-square $\left(\mathrm{X}^{2}\right)$ goodness of fit was used for the reef habitat area and reef accretion.

The relationship of the structure and diversity of the coral assemblages and ensembles with environmental variables per reef was evaluated with a canonical redundancy analysis (RDA) (Legendre and Legendre, 1998). Three matrices were constructed for the coral structure, each one with the covers at species and family level, such as ensembles. For coral diversity, another three matrices were constructed with Hill's numbers, each one for species, families and ensembles. Subsequently, all the matrices were transformed with Hellinger (Legendre and Gallagher, 2001). The environmental matrix was constructed with the live coral cover, the covers of algae, sand and calcareous substrate, as well as with the reef habitat area and topographic complexity. The statistical significance was tested with 9999 permutations in the CANOCO 4.5 program (Biometris, ter Braak and Šmilauer, 2002).

In order to explain several specific relationships between coral community parameters, simple and multiple regressions were generated by forward selection on RDA at species level. The dependent variables corresponded to the values of the first dimension of an NMDS generated with the species' covers or Hill's numbers per reef, which represented the variation of the structure and diversity of the coral assemblage. Other dependent variables were the live coral cover and Hill's numbers, analyzed individually. The independent variables were the covers of Orbicella annularis and O. faveolata (Orbicella = Montastraea, sensu Budd et al., 2012), the covers of algae and calcareous substrate, reef habitat area and topographic complexity. Live coral cover was used as dependent or independent variable, depending on the analyzed model. The Trace statistic was used as a determination coefficient and it was tested with 9999 permutations (CANOCO 4.5, Biometris, ter Braak and Šmilauer, 2002).

\section{RESULTS}

\section{CORAL ASSEMBLAGE STRUCTURE}

The structure and diversity of the coral assemblages presented different patterns among the reefs of the northern zone in contrast to those located in the central and southern zones (Table $\mathbf{1}$ ). In the northern zone the reefs presented partial reef development, which was limited to shallow areas. Punta Nizuc and Puerto Morelos showed similar compositions of species, families and ensembles, but different to those observed in Punta Maroma, with the exception of the structure of the families between Puerto Morelos and Punta Maroma that did not show strong dissimilarities (Table 1). In Punta Nizuc and Puerto Morelos, the dominant species were Acropora palmata, Siderastrea spp., Pseudodiploria strigosa; the dominant families were Acroporidae, Favidae, and Siderastreidae; and the dominant ensembles were branching, semispheric and brain corals (Table 2).

Punta Maroma presented a different coral development compared to other reefs, with not the same species, families and ensembles composition than the northern, central and southern reefs. It is possible that this is a transition area through a more continuous reef development like central and southern zones. The dominant species in this reef were Agaricia tenuifolia, Siderastrea spp., $O$. annularis and Porites porites; the dominant families were Favidae, Siderastreidae, Agaricidae and Poritidae;

Table 1 | One Way ANOSIM comparisons among coral assemblages at nsMBRS.

\begin{tabular}{|c|c|c|c|c|c|}
\hline Tests & Zones & Reef sites & Level & R statistic & Significance* \\
\hline \multirow[t]{6}{*}{ Pairwises } & NZ vs. CZ-SZ & 11 sites & $\mathrm{Sp}, \mathrm{F}, \mathrm{En}$ & $0.21<R<0.93$ & $0.000<p<0.05$ \\
\hline & & PN vs. PMa & $\mathrm{Sp}, \mathrm{F}, \mathrm{En}$ & $0.64<R<0.81$ & $p<0.001$ \\
\hline & & PMo vs. PMa & $\mathrm{Sp}, \mathrm{En}$ & $0.47<R<0.79$ & $p<0.001$ \\
\hline & & Ta vs. PA & $\mathrm{F}, \mathrm{En}$ & $0.18<R<0.23$ & $0.005<p<0.05$ \\
\hline & & Ta vs. Ma & $\mathrm{Sp}, \mathrm{F}, \mathrm{En}$ & $0.12<R<0.19$ & $0.01<p<0.05$ \\
\hline & & Ta vs. Xa & $\mathrm{Sp}, \mathrm{F}, \mathrm{En}$ & $0.15<R<0.19$ & $0.01<p<0.05$ \\
\hline
\end{tabular}

Codes: NZ, north zone; CZ, central zone; SZ, south zone; PN, Punta Nizuc; PMo, Puerto Morelos; PMA, Punta Maroma; Ta, Tampalam; PA, Punta Allen; Ma, Mahahual; Xa, Xahuyxol; Sp, species; F, families; En, ensemble.

${ }^{*}$ Statistical significance was presented like a ratio instead of percentage. Bold letters show a statistical significance with $\alpha=0.05$.

+ These results did not include comparison between Tampalan vs. Punta Allen, Mahahual and Xahuayxol. 
Table 2 | SIMPER's results taking into account the 95\% contribution of coral species, family and ensemble by reef site at nsMBRS.

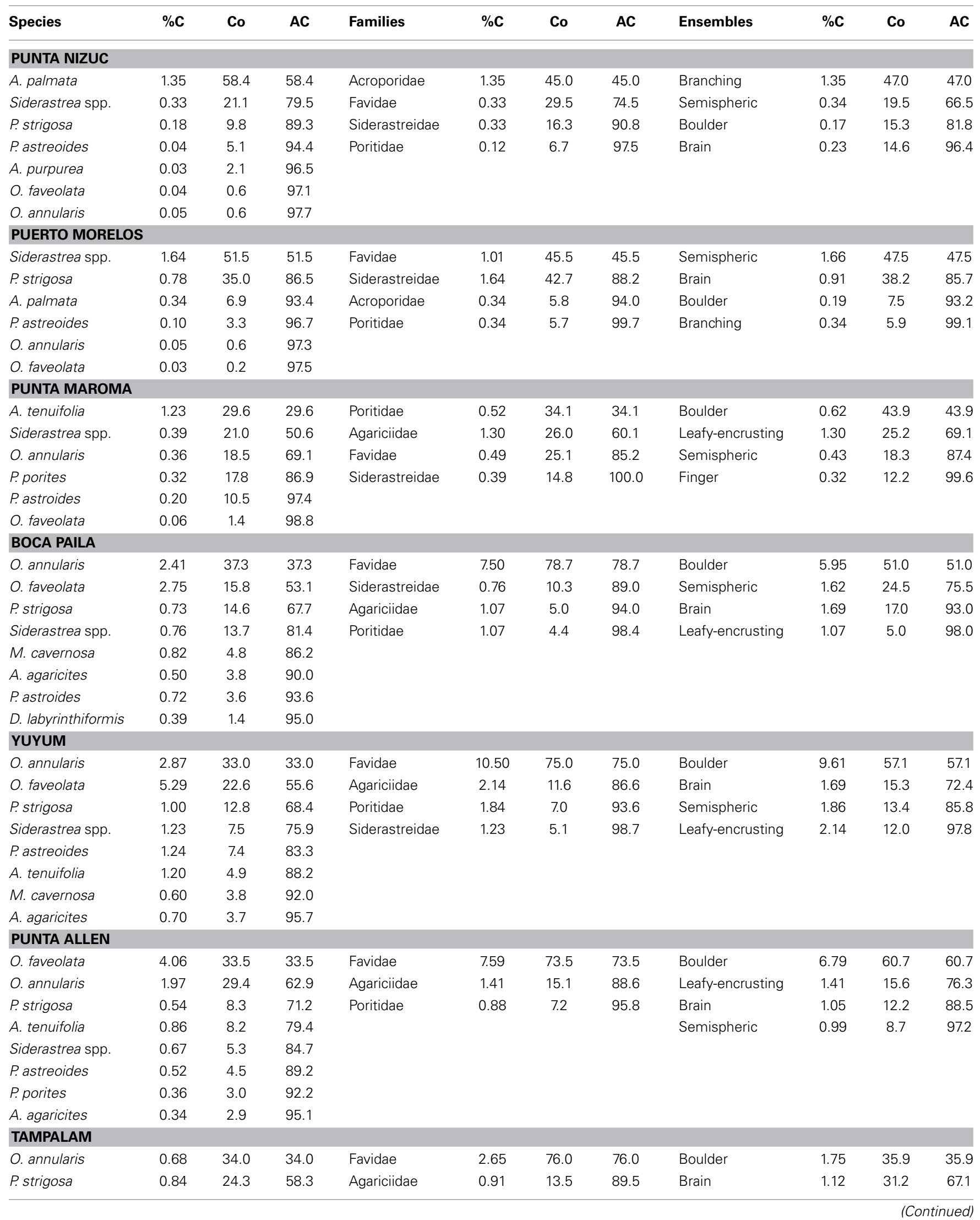


Table 2 | Continued

\begin{tabular}{|c|c|c|c|c|c|c|c|c|c|c|c|}
\hline Species & $\% \mathrm{C}$ & Co & $\mathrm{AC}$ & Families & $\% \mathrm{C}$ & Co & $A C$ & Ensembles & $\% \mathrm{C}$ & Co & $A C$ \\
\hline Siderastrea spp. & 0.37 & 6.9 & 65.2 & Poritidae & 0.41 & 4.2 & 93.7 & Semispheric & 0.61 & 16.0 & 83.2 \\
\hline A. agaricites & 0.15 & 6.7 & 71.9 & Siderastreidae & 0.37 & 4.1 & 97.8 & Leafy-encrusting & 0.91 & 14.6 & 97.8 \\
\hline P. astreoides & 0.36 & 6.1 & 78.0 & & & & & & & & \\
\hline P. clivosa & 0.15 & 4.9 & 82.9 & & & & & & & & \\
\hline O. faveolata & 0.61 & 4.8 & 87.7 & & & & & & & & \\
\hline A. tenuifolia & 0.64 & 4.1 & 91.8 & & & & & & & & \\
\hline M. cavernosa & 0.17 & 4.0 & 95.8 & & & & & & & & \\
\hline \multicolumn{12}{|l|}{ EL PLACER } \\
\hline O. annularis & 1.02 & 28.5 & 28.5 & Favidae & 4.71 & 75.8 & 75.8 & Boulder & 4.17 & 43.3 & 43.3 \\
\hline P. strigosa & 0.76 & 24.5 & 53.0 & Agariciidae & 1.13 & 9.9 & 85.7 & Brain & 1.19 & 29.5 & 72.8 \\
\hline O. faveolata & 2.25 & 12.3 & 65.3 & Poritidae & 1.41 & 8.1 & 93.8 & Semispheric & 0.54 & 12.4 & 85.2 \\
\hline Siderastrea spp. & 0.31 & 8.5 & 73.8 & Siderastreidae & 0.31 & 5.1 & 98.9 & Leafy-encrusting & 1.13 & 11.0 & 96.2 \\
\hline$P$. astreoides & 0.75 & 7.0 & 80.8 & & & & & & & & \\
\hline A. agaricites & 0.40 & 4.7 & 85.5 & & & & & & & & \\
\hline P. porites & 0.66 & 3.9 & 89.4 & & & & & & & & \\
\hline A. tenuifolia & 0.49 & 2.7 & 92.1 & & & & & & & & \\
\hline P. clivosa & 0.15 & 2.1 & 94.2 & & & & & & & & \\
\hline O. cavernosa & 0.20 & 2.1 & 96.3 & & & & & & & & \\
\hline \multicolumn{12}{|l|}{ MAHAHUAL } \\
\hline O. annularis & 2.99 & 35.7 & 35.7 & Favidae & 8.28 & 71.0 & 71.0 & Boulder & 7.32 & 59.9 & 59.9 \\
\hline O. faveolata & 3.69 & 23.3 & 59.0 & Agariciidae & 3.04 & 17.0 & 88.0 & Leafy-encrusting & 3.04 & 18.6 & 78.5 \\
\hline A. tenuifolia & 2.42 & 14.3 & 73.3 & Poritidae & 1.31 & 8.2 & 96.2 & Brain & 1.21 & 8.1 & 86.6 \\
\hline P. strigosa & 0.95 & 7.4 & 80.7 & & & & & Semispheric & 0.99 & 7.8 & 94.4 \\
\hline P. porites & 0.80 & 6.3 & 87.0 & & & & & Finger & 1.04 & 5.2 & 99.6 \\
\hline Siderastrea spp. & 0.68 & 4.6 & 91.6 & & & & & & & & \\
\hline \multicolumn{12}{|l|}{ XAHUAYXOL } \\
\hline O. faveolata & 4.17 & 32.0 & 32.0 & Favidae & 8.33 & 80.8 & 80.8 & Boulder & 7.42 & 64.7 & 64.7 \\
\hline O. annularis & 1.64 & 22.0 & 54.0 & Siderastreidae & 1.49 & 7.7 & 88.5 & Brain & 1.55 & 17.8 & 82.5 \\
\hline P. strigosa & 0.93 & 14.5 & 68.5 & Poritidae & 1.16 & 7.7 & 96.2 & Semispheric & 1.74 & 12.4 & 94.9 \\
\hline Siderastrea spp. & 1.49 & 11.2 & 79.7 & & & & & Leafy-encrusting & 0.57 & 2.9 & 97.8 \\
\hline$P$. astreoides & 0.81 & 8.6 & 88.3 & & & & & & & & \\
\hline A. agaricites & 0.54 & 3.4 & 91.7 & & & & & & & & \\
\hline O. franksi & 0.81 & 3.2 & 94.9 & & & & & & & & \\
\hline P. porites & 0.36 & 1.3 & 96.2 & & & & & & & & \\
\hline \multicolumn{12}{|l|}{ XCALAK } \\
\hline O. annularis & 1.88 & 35.8 & 35.8 & Favidae & 6.83 & 87.1 & 87.1 & Boulder & 5.48 & 59.0 & 59.0 \\
\hline P. strigosa & 0.93 & 20.5 & 56.3 & Siderastreidae & 0.48 & 6.5 & 93.6 & Brain & 1.50 & 26.5 & 85.5 \\
\hline O. faveolata & 2.61 & 17.1 & 73.4 & Poritidae & 0.55 & 5.5 & 99.1 & Semispheric & 0.94 & 13.6 & 99.1 \\
\hline Siderastrea spp. & 0.48 & 10.1 & 83.5 & & & & & & & & \\
\hline$P$ astreoides & 0.55 & 8.6 & 92.1 & & & & & & & & \\
\hline P. clivosa & 0.34 & 4.2 & 96.3 & & & & & & & & \\
\hline
\end{tabular}

Codes: \%C, cover (\%); Co, contribution (\%); AC, Accumulated contribution (\%).

and the ensembles that predominated were boulder, encrusting, semispheric and finger corals (Table 2).

In the central and southern zones, the reefs presented greater reef development, which extends from shallow areas in reef lagoons to deeper areas on the terraces. The coral assemblages were similar for most of the reefs (Table 1), with the exception of Tampalam, which presented differences with Mahahual, Xahuayxol and Punta Allen. In general, the dominant species were O. annularis, O. faveolata, P. strigosa y Siderastrea spp., Agaricia agaricites, and $A$. tenuifolia; the most important familes were
Favidae, Agaricidae, and Siderastreidae; and the ensembles with the greatest contribution were the submassive, brain, hemispheric and encrusting corals (Table 2). The Orbicella species complex contributed among 40 and $68 \%$ to total of coral assemblages.

In Tampalam, the corals grow in a more isolated way and present poor reef developments. Its assemblage was constituted by the species O. annularis, P. strigosa, Siderastrea spp., A. agaricites, Porites astroides, and Pseudodiploria clivosa; the families Favidae, Agaricidae, and Poritidae; and the ensembles of submassive, brain, hemispheric and encrusting corals (Table 2 ). 


\section{SPECIES, FAMILY AND ENSEMBLE DIVERSITY}

A total of 30 species of corals were recorded, belonging to 9 families and 9 ensembles in the nsMBRS. Reefs located in the northern zone had the lowest species richness $\left(N_{0}\right)$ while the reefs located in the central and southern zones exhibited the highest values (Table 3). Similarly, the evenness indices $\left(N_{1}, N_{2}\right.$ and $\left.N_{21}\right)$, estimated at species level, presented a similar pattern to that of species richness (Table 3). When the evenness indices were analyzed by family and ensemble a different configuration was found. Several reefs with intermediate richness had the lowest evenness, while the reefs with the highest richness and those with the lowest richness displayed similar evenness values (Table 3).

In general, a similar clustering configuration was observed with the analysis at species and ensemble level (Figure 2). In both levels, five groups were identified (Figures 2A,C): (1) group 1, associated with the reefs of Yuyum, Punta Allen, Mahahual, and Xahuayxol, which presented greater species and ensemble richness with a moderate evenness; (2) groups 2, 3, and 4 integrated by the reefs of El Placer, Boca Paila, Xcalak, and Tampalam, which have an intermediate species and ensemble richness and low evenness; and (3) group 5 incorporated the reefs of Punta Nizuc, Puerto Morelos, and Punta Maroma, with the lowest richness but a high evenness. The clustering configuration at family level was different, and four groups were identified (Figure 2B): (1) group 1 incorporated the reefs of Mahahual, El Placer, Xahuayxol, Punta Allen, Yuyum, and Boca Paila for their greater species and family richness but lowest evenness; (2) groups 2 and 3 which separated the reefs of Xcalak and Tampalam with an intermediate species and family richness and the greatest evenness; (3) group 4 joined the reefs of Punta Nizuc, Punta Maroma and Puerto Morelos with the lowest species and family richness and an intermediate evenness.

\section{ENVIRONMENTAL FACTORS}

The average live coral cover varied among the reefs from 2.2 to $13.8 \%$. The greatest coral covers were estimated in the central and southern zones, particularly in Mahahual, Yuyum, and Boca Paila reefs (Figure 3A). Algae presented the highest substrate covers, with an average that varied among reefs from 21.1 to $59.3 \%$. The highest values were observed in Puerto Morelos, Boca Paila, and Yuyum reefs, while the lowest were found in Mahahual reef (Figure 3B). The average sand cover varied from $1.1 \%$ in Yuyum to $16.1 \%$ in Puerto Morelos reefs (Figure 3C). The mean calcareous substrate cover was from 2.9 to $24.8 \%$; the highest values were found in Mahahual and Tampalam reefs (Figure 3D). The topographic complexity increased along a latitudinal gradient from north to south, with the highest values in Mahahual, Xahuayxol, and Xcalak reefs (Figure 3E). The reef habitat area fluctuated from 0.56 to $2.68 \mathrm{~km}^{2}$, the reefs of the central and southern zones have more extensive areas, particularly Yuyum, Mahahual, and Boca Paila reefs (Figure 3F).

\section{CORAL BIODIVERSITY AND ENVIRONMENTAL FACTORS}

The RDA showed that the contribution and abundance of $O$. annularis and $O$. faveolata mainly explained the variation of the coral species diversity among reefs (Trace $=0.84, p<$ 0.001 ). Maximum biodiversity was found when these species complex had a contribution greater than $54 \%$ and a cover greater than 5.5\% (Tables 2, 3). This occurred in Yuyum, Punta Allen, Mahahual, and Xahuayxol reefs. If these species showed a contribution among 39 and 52\%, and a cover from 1 to 5\% (Table 2), the reefs presented an intermediate biodiversity (Table 3), as it was the case in Boca Paila, El Placer, Xcalak, and Tampalam reefs. If the contribution was less than $20 \%$ and the cover presented values below $0.5 \%$ (Table 2 ), the reefs presented a low biodiversity

Table 3 | Hill's numbers estimated by reef at nsMBRS.

\begin{tabular}{|c|c|c|c|c|c|c|c|c|c|c|c|}
\hline & PN & PMo & PMa & BP & $\mathbf{Y X}$ & PA & $\mathrm{Ta}$ & EP & $\mathbf{M a}$ & $\mathrm{Xa}$ & $\mathbf{X c}$ \\
\hline \multicolumn{12}{|c|}{ SPECIES LEVEL } \\
\hline$N_{0}$ & 14 & 11 & 14 & 22 & 28 & 25 & 22 & 24 & 25 & 23 & 19 \\
\hline$N_{1}$ & 4.32 & 4.36 & 5.49 & 11.42 & 9.93 & 9.00 & 11.76 & 11.82 & 8.61 & 8.86 & 7.69 \\
\hline$N_{2}$ & 2.56 & 3.03 & 3.79 & 7.83 & 6.34 & 5.31 & 9.44 & 8.05 & 6.11 & 5.78 & 5.45 \\
\hline$N_{b}$ & 7.11 & 3.59 & 4.70 & 2.74 & 11.71 & 10.68 & 0.79 & 4.12 & 10.27 & 8.35 & 5.85 \\
\hline$N_{21}$ & 0.59 & 0.69 & 0.69 & 0.68 & 0.64 & 0.59 & 0.80 & 0.68 & 0.71 & 0.65 & 0.71 \\
\hline \multicolumn{12}{|c|}{ FAMILY LEVEL } \\
\hline$N_{0}$ & 6 & 5 & 6 & 8 & 8 & 9 & 7 & 9 & 9 & 9 & 8 \\
\hline$N_{1}$ & 3.32 & 3.30 & 3.61 & 3.42 & 3.31 & 2.89 & 3.89 & 3.78 & 3.25 & 2.90 & 1.97 \\
\hline$N_{2}$ & 2.46 & 2.72 & 3.13 & 2.20 & 2.27 & 1.97 & 2.86 & 2.65 & 2.38 & 1.97 & 1.42 \\
\hline$N_{b}$ & 0.21 & $0^{*}$ & $0^{*}$ & 2.37 & 2.41 & 4.12 & 0.24 & 2.56 & 3.35 & 4.11 & 4.60 \\
\hline$N_{21}$ & 0.74 & 0.82 & 0.86 & 0.64 & 0.68 & 0.68 & 0.73 & 0.70 & 0.73 & 0.67 & 0.72 \\
\hline \multicolumn{12}{|c|}{ ENSEMBLE LEVEL } \\
\hline$N_{0}$ & 6 & 6 & 6 & 7 & 8 & 9 & 7 & 8 & 9 & 8 & 7 \\
\hline$N_{1}$ & 3.51 & 3.55 & 3.69 & 4.12 & 3.71 & 3.49 & 4.70 & 4.23 & 3.83 & 3.38 & 2.65 \\
\hline$N_{2}$ & 2.50 & 2.80 & 3.11 & 3.06 & 2.63 & 2.39 & 4.18 & 3.18 & 2.87 & 2.37 & 2.02 \\
\hline$N_{b}$ & $0^{*}$ & $0^{*}$ & $0 *$ & $0^{*}$ & 1.64 & 3.11 & $0 *$ & 0.58 & 2.29 & 2.24 & 2.31 \\
\hline$N_{21}$ & 0.71 & 0.78 & 0.84 & 0.74 & 0.71 & 0.68 & 0.89 & 0.75 & 0.75 & 0.70 & 0.76 \\
\hline
\end{tabular}

${ }^{*}$ When $N_{0}$ showed low values $N_{b}$ could be a negative value, in this case we used a zero. 
A Species
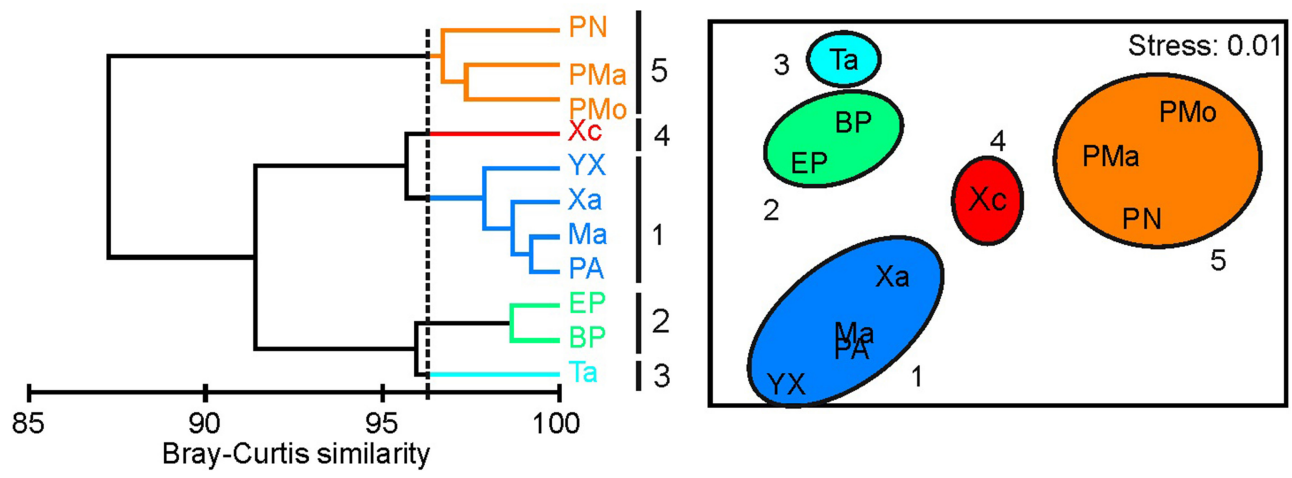

B Families
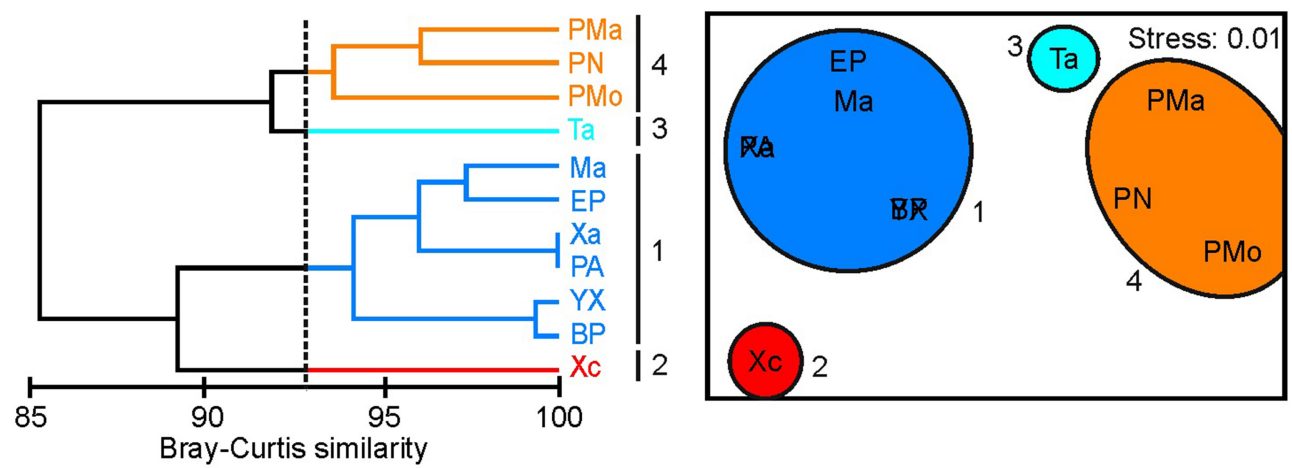

\section{c Ensembles}
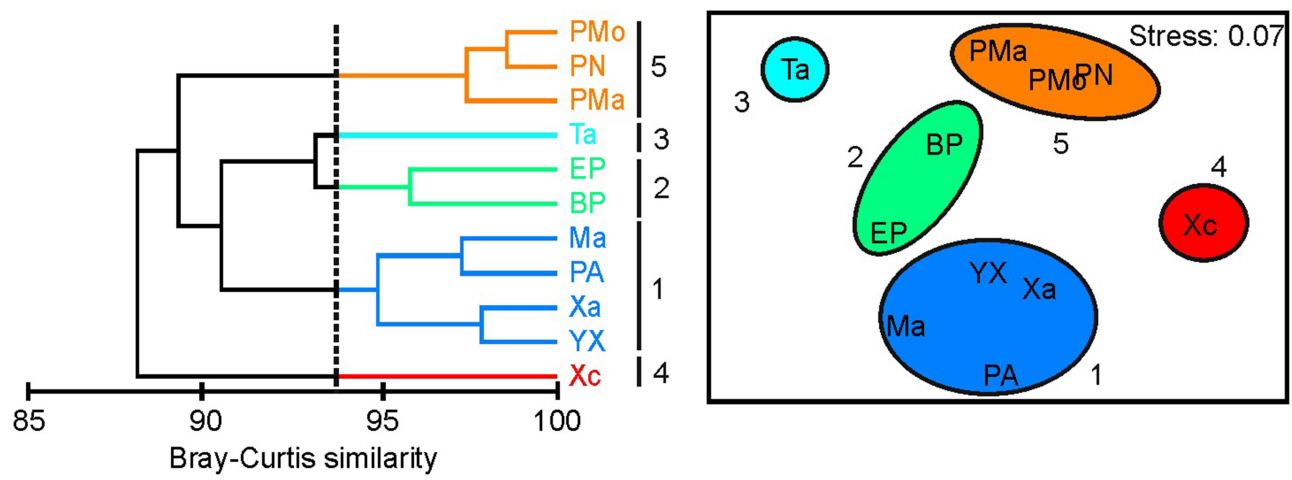

FIGURE 2 | Cluster analysis (CA) and non-metric multidimensional scaling (NMDS) based on Hill's numbers estimated by coral species, families and ensembles. (A) Species; (B) Families; (C) Ensembles. Note: numbers represent clusters and isolated reefs. Reef codes correspond to Figure 1.

(Table 3). This occurred in Punta Nizuc, Puerto Morelos, and Punta Maroma reefs.

The results of the RDA also showed that the live coral cover, reef habitat area, sand cover and topographic complexity were mainly related to the structure and diversity of corals at species, family and ensemble level. The correlation values ranged from 0.72 to 0.98 (Tables S1, S2). Among 66.2 and 74.7\% of the variation was explained for the coral assemblage structure, and from 99.2 to $99.7 \%$ for coral diversity (Tables S1, $\mathrm{S} 2)$. The RDA ordinations showed that axis 1 was related to the reef sites with similar structure and coral diversity hence the reefs of the central and southern zones were separated from those in the northern zone (Figures 4A-C). Mahahual, El Placer, Xahuayxol, Punta Allen, Yuyum reefs were identified with high biodiversity, while Boca Paila, El Placer, Xcalak, and Tampalam presented an intermediate biodiversity, and Punta Nizuc, Puerto Morelos and Punta Maroma showed low biodiversity (Figures 4D-F).

The coral assemblage structure and diversity ordinations showed that the reef habitat area, live coral cover and topographic complexity were associated with the complex of species $O$. annularis and $O$. faveolata, with the Favidae family and 


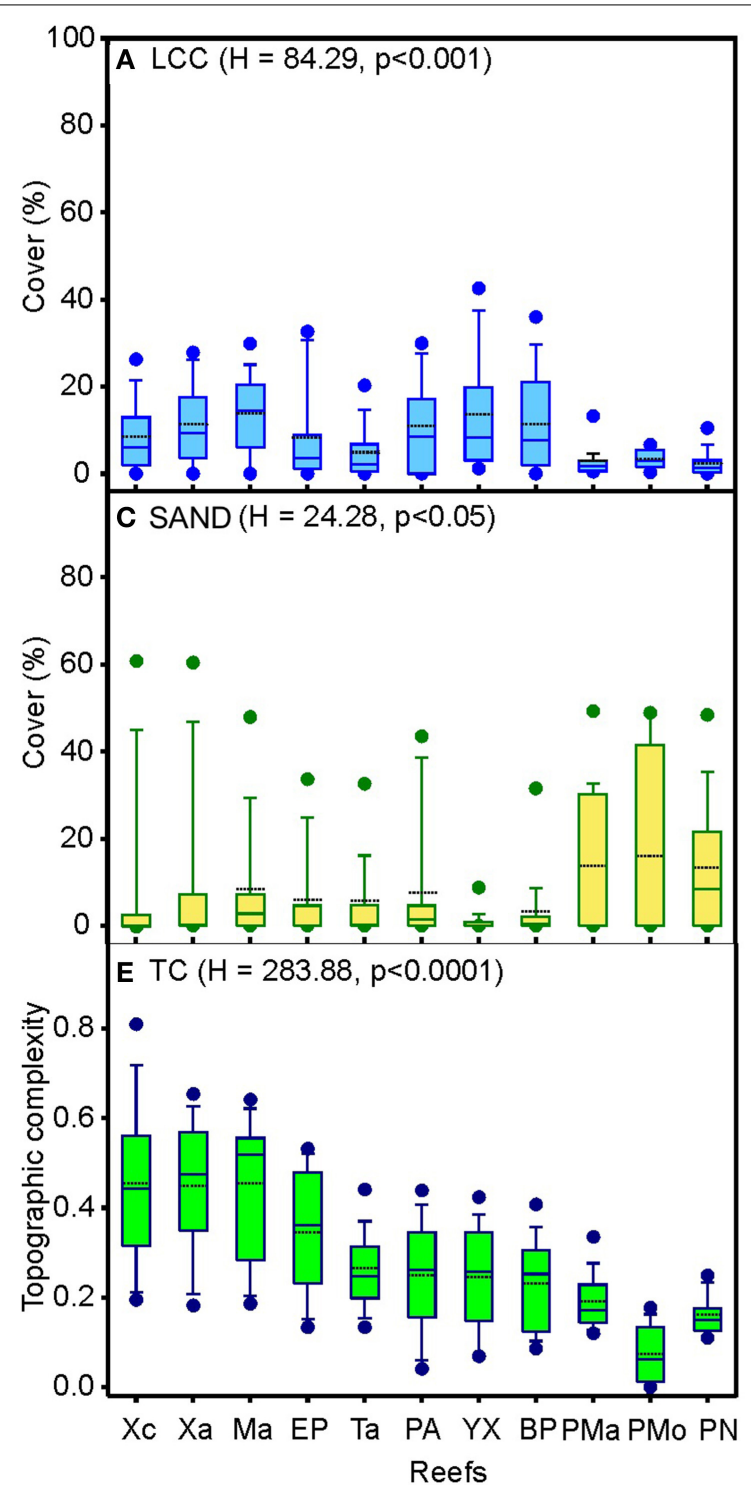

FIGURE 3 | Box plots and bar charts of the habitat structure and environmental variables per reef site at nsMBRS. (A) Live coral cover (LCC); (B) Algae cover (ALGAE); (C) Sand cover (SAND); (D) Calcareous substrate cover (CSUB); (E) Topographic complexity (TC); (F) Reef habitat

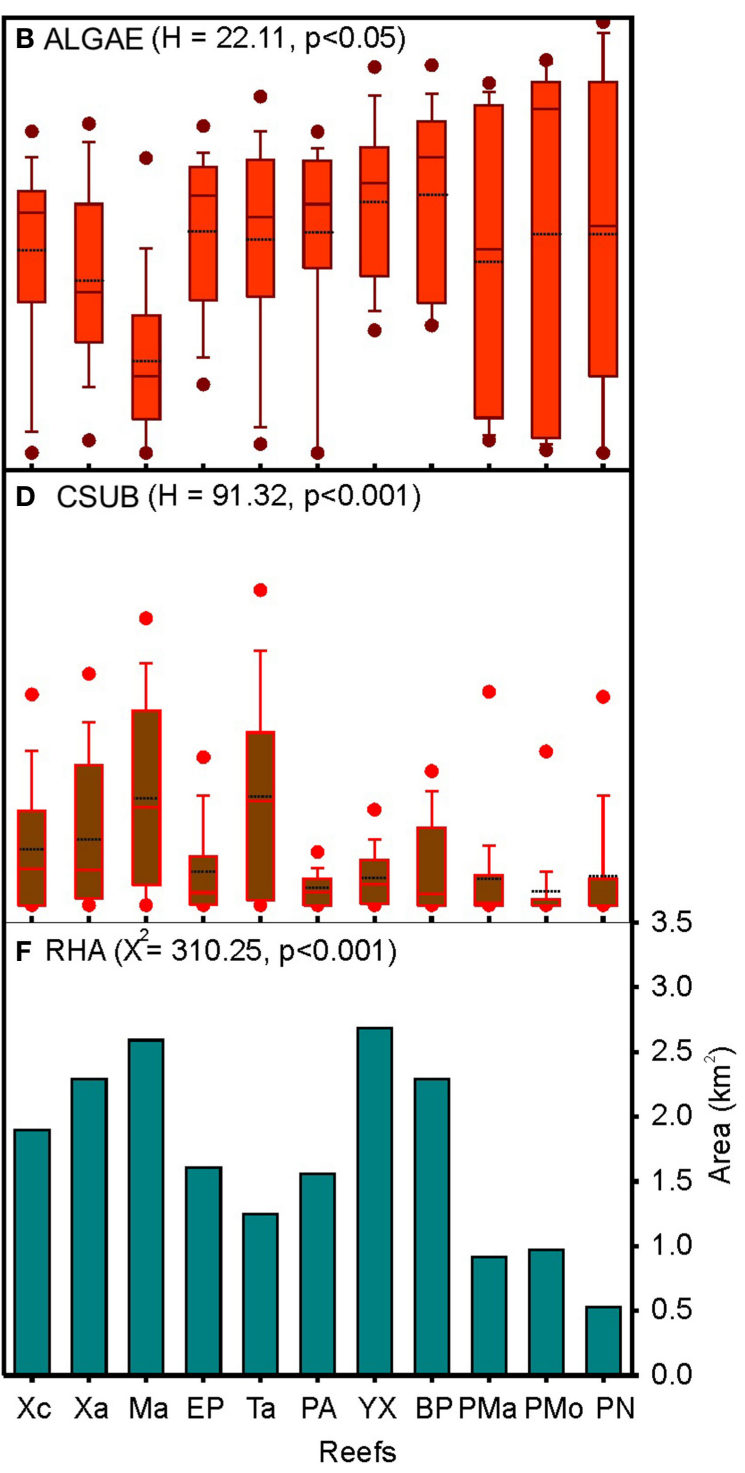

area (RHA). In (A-E) are drawn the means (dotted line), medians (solid line), $75 \%$ (box) and 95\% (error bars) percentiles, and maximum and minimum values (solid-black circles). Kruskal-Wallis $(H)$ y Chi-square $\left(X^{2}\right)$ tests are showed between parentheses. Reef codes correspond to Figure 1. with the boulder corals ensemble, which dominated on the reefs of the central and southern zones (Figures $4 \mathrm{~A}-\mathrm{C}$ ). These environmental variables were also correlated with species richness $\left(N_{0}\right)$, which predominantly determines the coral diversity of the reefs (Figures 4D-F). Sand cover presented an inverse relationship between the patterns of coral richness and evenness; hence it was correlated with the reefs of the northern zones and the species A. palmata and Siderastrea spp., the families Acroporidea and Siderastreidae and the branched and semispheric corals (Figures 4A-C). Similarly, sand was related to Hill's evenness $\left(N_{21}\right)$ at the family and ensemble level (Figures 4D-F). Calcareous substrate was weakly associated with live coral cover, reef habitat area and topographic complexity.
Algae were weakly correlated with coral assemblage structure and did not present a defined pattern among ordinations. The indexes $N_{1}, N_{2}$ y $N_{b}$ presented different patterns; at species level they were associated with calcareous substrate and algae, while at family and ensemble level they were inversely related to live coral cover, reef habitat area, topographic complexity and coral species richness $\left(N_{0}\right)$. Finally, $N_{b}$ was inversely related to $N_{1}$ and $N_{2}$.

\section{CORAL STRUCTURE AND DIVERSITY}

Reef habitat area, live coral cover and the species $O$. annularis and O. faveolata were found to influence the structure and diversity of the corals of the nsMBRS (Figure 5A). This was accounted for 


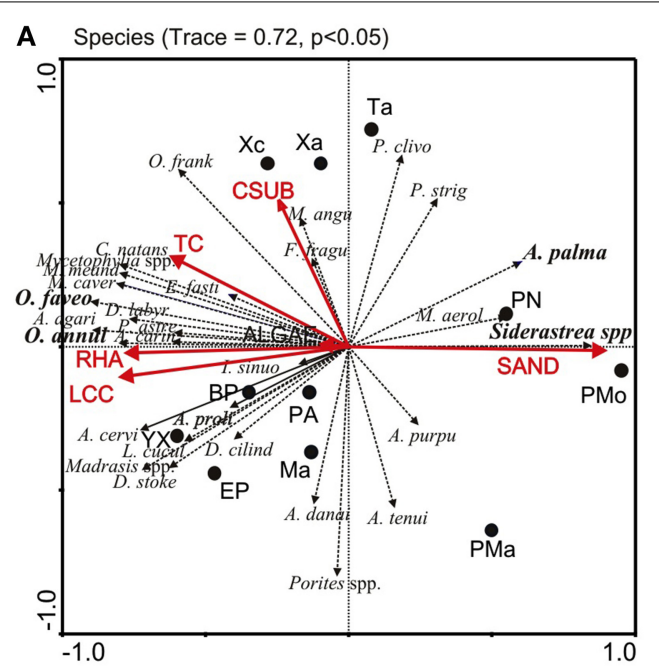

C Ensembles (Trace $=0.75, p<0.05)$

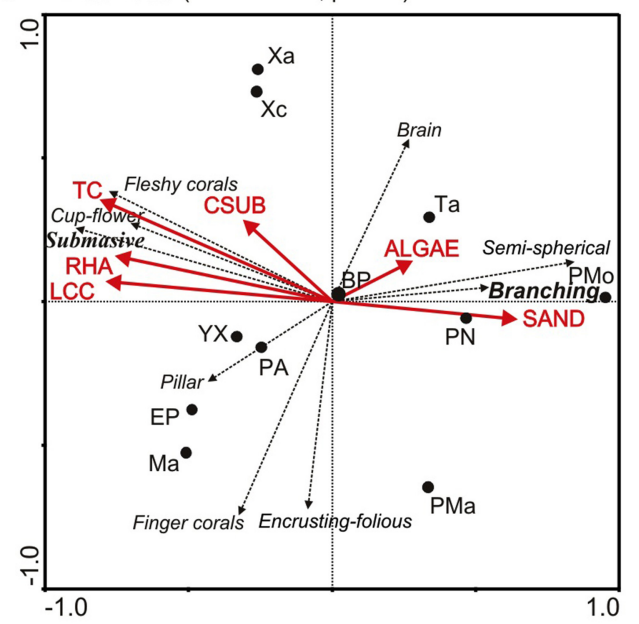

E Family diversity $($ Trace $=0.91, \mathrm{p}<0.05)$

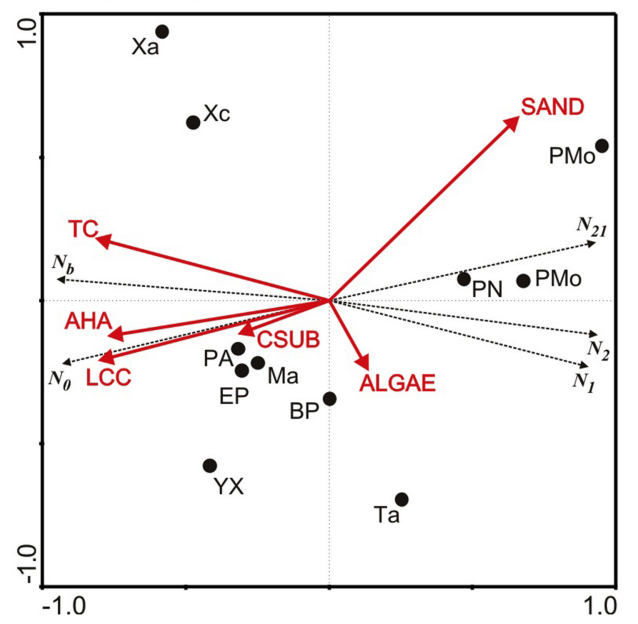

FIGURE 4 | RDA ordinations of coral structure assemblage and evenness diversity (Hill's number series) per species, families and ensemble in each reef of nsMBRS. Coral assemblage: (A) Species, (B) Families, (C)

Ensembles. Evenness diversity: (D) Species, (E) Families, (F) Ensembles. (1) (A) Shows the first letter of the genus and the first five letters of the name of the species, or full name of the genus and species abbreviation (sp. or spp.);

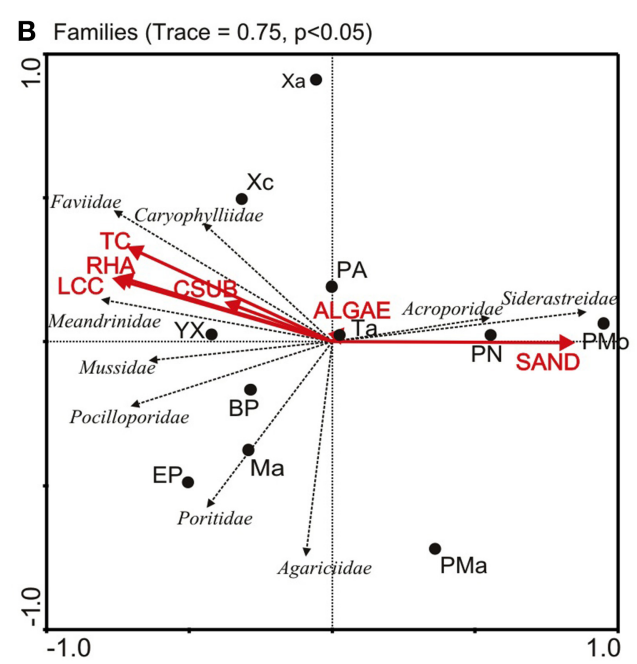

D Species diversity $($ Trace $=0.88, p<0.01)$

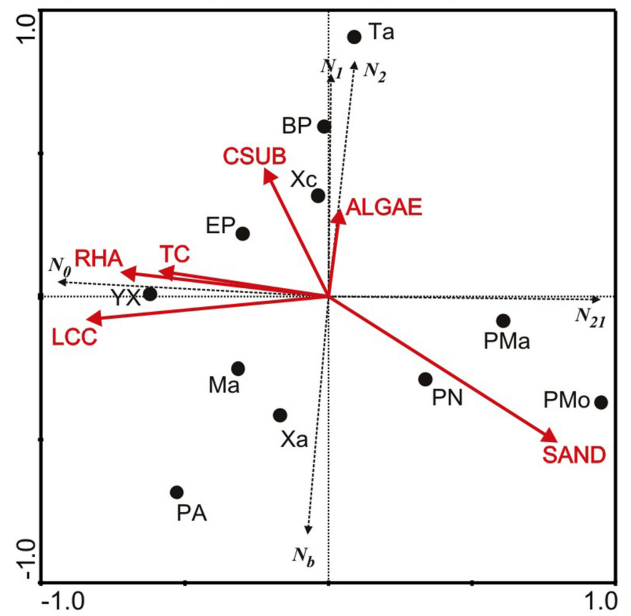

F Ensembles diversity $($ Trace $=0.90, p<0.05)$

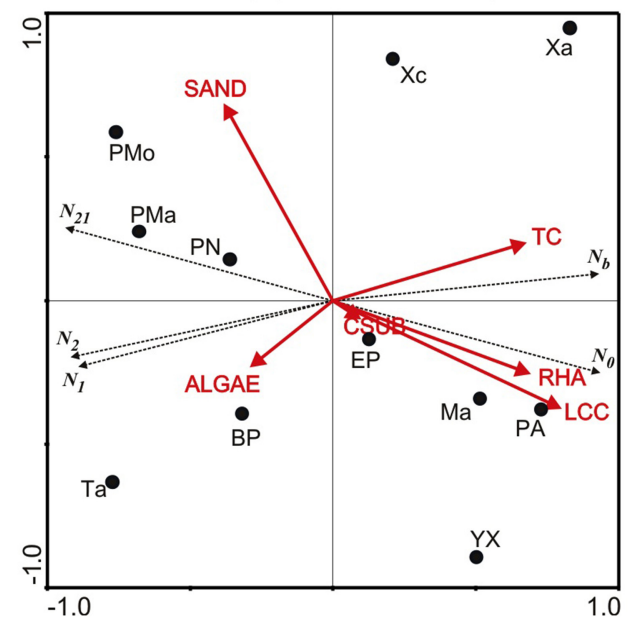

(2) Arrows with solid lines representing environmental variables. The arrows with segment lines show the projections of species, families and ensembles. Codes: RHA is reef habitat area; LCC is live coral cover; TC is topographic complexity; CSUB is calcareous substrate; $N_{0}, N_{1}, N_{2}, N_{b}$, and $N_{21}$ are Hill's number series (see Materials and Methods section). Reef codes correspond to Figure 1. 


\section{A Coral diversity models}

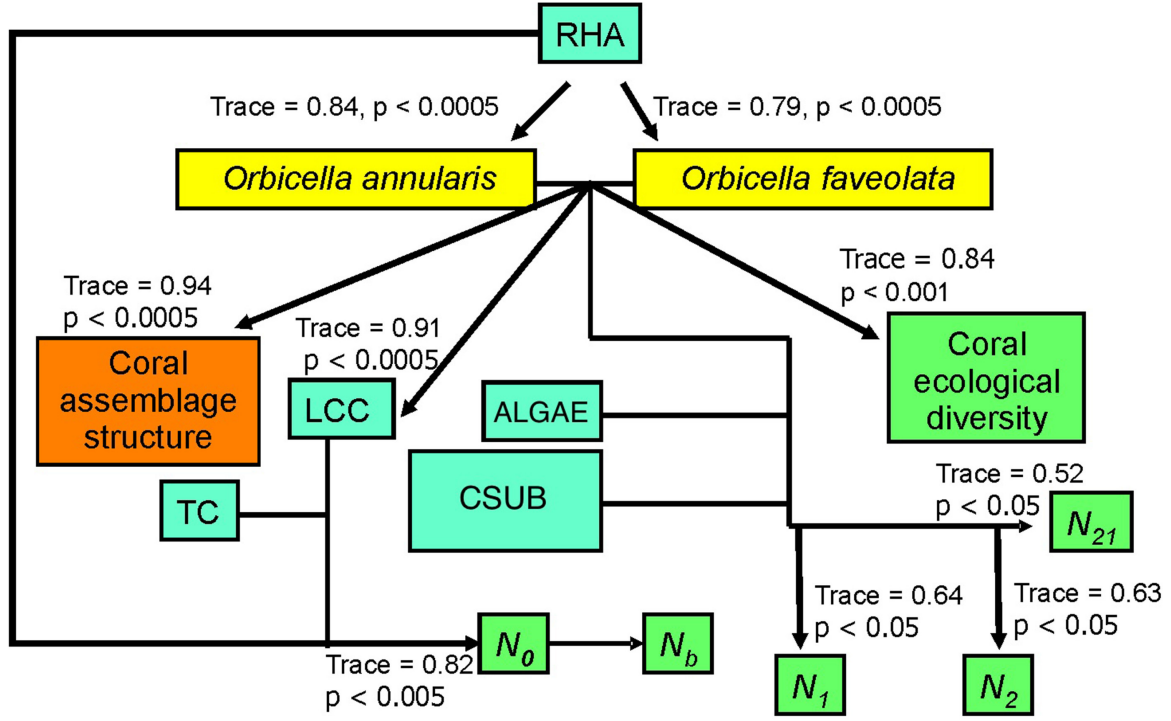

B Reef bio-construction

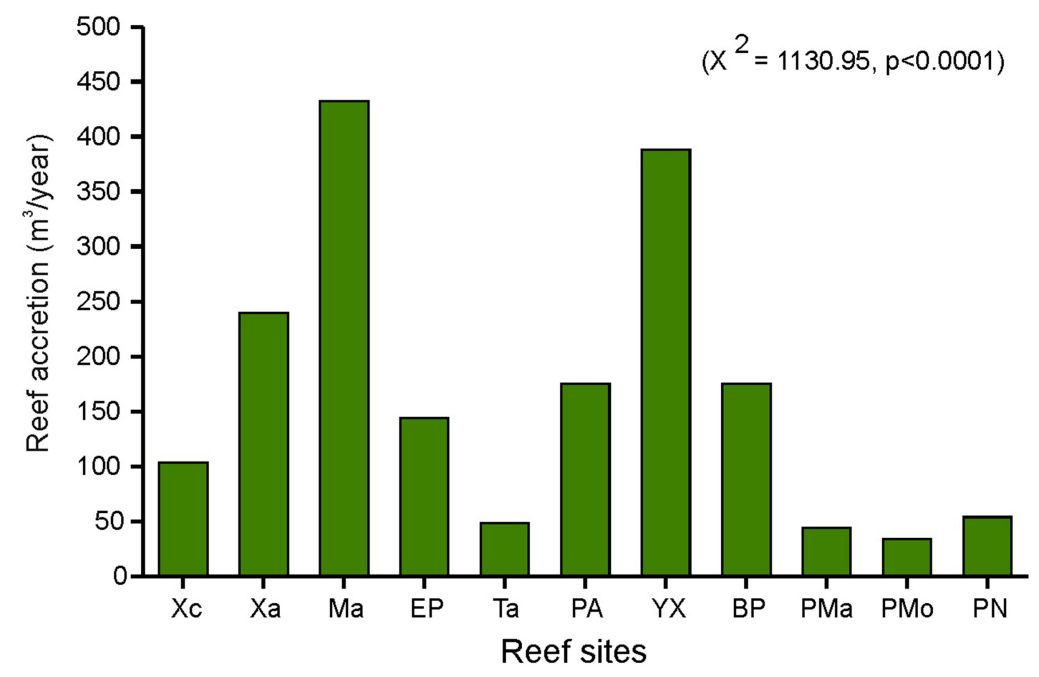

FIGURE 5 | RDA models that explain the coral diversity of reefs at nsMBRS, and bio-construction estimated by each reef. (A) Coral diversity. All RDA models were carried out at species level. Codes: RHA is reef habitat area; LCC is live coral cover; TC is topographic complexity; CSUB is calcareous substrate; $N_{0}, N_{1}, N_{2}, N_{b}$, and $N_{21}$ are Hill's number series (see Materials and Methods section). (B) Bio-construction expressed as accretion $\left(\mathrm{m}^{-3}\right)$ by reef. Chi-square $\left(\mathrm{X}^{2}\right)$ tests are showed between parentheses. Reef codes correspond to Figure 1.
(Figure 5A): (1) O. annularis and O. faveolata covers constituted the main bulk of the live coral cover of reefs, which primarily shaped the structure and diversity of coral species; (2) the greater the increase in $O$. annularis and $O$. faveolata cover the greater the reef habitat area in the reefs; (3) the reef habitat area combined with the live coral cover and topographic complexity, determined coral species richness $\left(N_{0}\right)$; $(4)$ to greater richness more species with lower abundance $\left(N_{b}\right)$; (5) O. annularis and O. faveolata covers, combined with algae and calcareous substrate covers, were related to the diversity $\left(N_{1}\right.$ and $\left.N_{2}\right)$ and evenness indexes $\left(N_{21}\right)$ (Figure 5A).

\section{REEF BIO-CONSTRUCTION}

The reef bio-construction varied with reef accretion values from 43.8 to $432.1 \mathrm{~m}^{-3}$ with strong differences among reefs (Figure 5B). The highest values were estimated by Mahahual, Yuyum, Xahuayxol, followed by Punta Allen, Boca Paila, El Placer, and Xcalak. The lowest values were estimated by Puerto Morelos, Punta Maroma, Punta Nizuc, and Tampalam (Figure 5B). The patterns found in the bio-construction per reef were similar to the results obtained from the analysis of the coral assemblage structure and diversity. The reefs with more complex assemblages and greater diversity presented the greatest bio-construction. 


\section{DISCUSSION CORAL STRUCTURE AND DIVERSITY}

The coral assemblage structure and diversity patterns varied among reefs mainly due to the differences that exist in the abundance of the dominant species, O. annularis and O. faveolata, and to the geomorphological conditions of each reef. The northern reefs present a reef crest and front with a small reef habitat area extension, while the central and southern reefs present a reef crest, front, slope and terrace with a large extension. The continental shelf of the nsMBRS has been shaped by the Río Hondo fault that extends from Belize to the north of the Yucatán Peninsula (Weidie, 1985). The characteristics of the fault cause the reefs of the northern zone to have a wide shelf with steeper slopes that limit the reef development to shallow surfaces $(<6 \mathrm{~m})$. In contrast, the sites of the central and southern zones have developed upon a wider continental shelf with shallow slopes and a large quantity of hard substrate. This supports a greater reef development with spurs and grooves that extend to depths of more than $60 \mathrm{~m}$. It favors the creation of more habitats from shallow to deep areas and high structural complexity.

The geomorphological differences can generate a differential development among the reefs. The reefs of the northern zone present partial, shallow reef developments. They were correlated with high sand cover, which indicated a smaller reef habitat area, low live coral cover and topographic complexity. Sand is a soft, unstable substrate that does not permit the massive development of corals in this area (Jordán-Dahlgren, 1993). The coral assemblage structure in the zone was dominated by species typical of shallow reefs. In Punta Nizuc and Puerto Morelos reefs, A. palmata (branched coral), Siderastrea spp. (hemispherical) and P. strigosa (brain) were dominant; while in Punta Maroma reef the dominant species were A. tenuifolia (encrusting-leafy), Siderastrea spp. and O. annularis (boulder) and P. porites (finger). A. palmata is one of the dominant species in shallow reefs of the Caribbean (Kramer, 2003), since it is an opportunistic species (r-strategy) with rapid growth that by way of fragmentation maintains its abundance. Equally A. palmata supports the waves, exposure to the air, heating and sedimentation (Harrison and Wallace, 1990; Lang and Chornesky, 1990). Semispheric (Siderastrea spp.) and brain (e.g., Pseudodiploria spp. and Diploria labyrinthiformis) corals are also resistant to the waves and possess high sediment cleaning rates (Sorokin, 1995). The encrusting-leafy (A. tenuifolia) and finger ( $P$. porites) corals present shapes that reduce the effect of the waves. Thus these species assemblages have been able to exist in adverse environments, but have been generating poor reef developments with low organism richness within the nsMBRS.

Reefs of the central and southern zones presented a greater habitat area than those of the north. These reefs have extensive reef developments with greater live coral cover, high topographic complexity and the greatest contribution of $O$. annularis and $O$. faveolata (boulder corals). These characteristics favor the formation of spur and groove systems. The structure of the coral assemblages at species, family and ensemble level was similar in the majority of these reefs. O. annularis, O. faveolata, P. strigosa, Siderastrea spp., and $P$. astreoides were the dominant species in these zones. These results corroborate those found by other studies in the nsMBRS (Gutiérrez et al., 1993; Jordán-Dahlgren, 1993; Jordán-Dahlgren and Rodríguez-Martínez, 2003; RuízZárate et al., 2003). The Orbicella species complex is characterized by possessing high rates of survival, regeneration from lesions and sediment cleaning (Lang and Chornesky, 1990; Sorokin, 1995; Brown, 1997). Furthermore, they are resistant to storm surges and are more competitive for substrate due to their aggressiveness and type of growth (Lang and Chornesky, 1990; Brown, 1997). In the Caribbean these species have contributed with the greatest relative live coral cover and are distributed from depths of 0-85 m (Sorokin, 1995; Kramer, 2003) dominating the forereef habitats (Mumby et al., 2008). In this study O. annularis and $O$. faveolata species complex were the most important reef builders in the nsMBRS, which agrees with other reports on this area (Gutiérrez et al., 1993; Ruíz-Zárate et al., 2003). Likewise, this study shows $P$. astreoides is another specie that significantly contributes for coral assemblage structure, due to its high frequency and coverage throughout the analyzed reefs at the beginning of 2000s. However, P. astreoides is currently considered one species that has become a more prominent component of coral reefs across the Caribbean Sea, because it is resilient to environmental stress, and by its "weedy" life-history strategy (Green et al., 2008). Also, $P$. astreoides has high demographic rates that reduce the risk of epizootics through increased average population turnover (Yakob and Mumby, 2011). But it has small colonies that contribute little to reef accretion and habitat architectural complexity (Alvarez-Filip et al., 2013). The acroporids did not present a significant contribution to the coral assemblages, as reported in previous studies (Jordán-Dahlgren, 1993). Since 1990 these species have decreased and in many of the reefs their skeletons are in growing position, which indicates biological mortalities, perhaps caused by the white band disease (Jordán-Dahlgren and Rodríguez-Martínez, 2003; Ruíz-Zárate et al., 2003), which has caused massive mortalities in other Caribbean reefs (Kramer, 2003).

The analyses of variation of the structure and diversity of the coral assemblages of the nsMBRS, at species, family, and ensemble level were explained by the reef habitat area, live coral cover, topographic complexity and the abundances of $O$. annularis and O. faveolata. Reef habitat area, live coral cover and topographic complexity were positively correlated with the cover of $O$. annularis and O. faveolata and their respective families and ensembles, as well as with the species richness $\left(N_{0}\right)$. The reef habitat area, live coral cover and topographic complexity are considered key variables that establish and maintain the biodiversity of coral reefs (Bellwood and Hughes, 2001; Arias-González et al., 2008; Alvarez-Filip et al., 2011, 2013). Larger areas contain more habitats and support more species, promote diversity on temporal scales, determine the size of populations and influence genetic diversity (Palumbi, 1997; Bellwood and Hughes, 2001). Coral species richness and distribution patterns depend on habitat characteristics and live coral cover (Tomascik et al., 1996; Guzmán et al., 2004; Arias-González et al., 2008). O. annularis and $O$. faveolata had a high contribution of live coral cover in reefs with greater reef habitat area and topographic complexity. Reef architectural complexity increases, and it is highest, on reef sites dominated by large, massive coral species, such as Orbicella spp., 
than in sites dominated by short-lived and stress-resistant coral species as Porites and Agaricia (Alvarez-Filip et al., 2011, 2013). Live coral cover directly influences coral species richness, given that the majority of them recruit and establish themselves on live coral (Nzali et al., 1998; Ruíz-Zárate et al., 2003). The topographic complexity produced mainly by the architecture of corals favors the survival and establishment of juvenile corals because it provides more nooks and crannies that are used as refuges to escape from grazing fish and environmental stress (Miller et al., 2000).

The high dominance of $O$. annularis and $O$. faveolata generated a low evenness in the coral assemblages. Therefore, the reefs with high and intermediate biodiversity, located in the central and southern zones, presented a greater number of species, families and ensembles but with a lower evenness. In contrast, the reefs with low biodiversity, located in the northern zone, had a greater evenness due to the low dominance of $O$. annularis and O. faveolata. These results highlighted that $O$. annularis and $O$. faveolata can be used as indicator species, due to the fact that their abundance and contribution influence the coral assemblage structure and diversity at nsMBRS.

\section{BIODIVERSITY AND BIO-CONSTRUCTION}

Corals are an assemblage that can be considered as an indicator of global biodiversity in coral reefs, since they are part of a bottom-up control into the food webs and are the most important bio-constructors of coral reef ecosystems. Furthermore, many of the species that inhabit coral reefs directly depend on the live coral cover and structure of the habitat that the corals build (Almany, 2004; Jones et al., 2004). Framework building in coral reefs is strongly dependent on the participation of all ensembles of building organisms, and composition of biota and bio-constructors diversity can influence outcome of bio-construction (Cocito, 2004). Our results showed that reefs with high coral species richness presented high live coral cover. This demonstrates that much of the biodiversity of the reefs depends on the structure and diversity of the corals, as well as on the live coral cover and topographic complexity they generate. This correspond also with other taxa in the same study area, which has showed a positive correlation between the reef habitat area, live coral cover, topographic complexity and the beta diversity of fish and corals (Arias-González et al., 2008, 2011).

The reefs with greater live coral cover present a greater biomass of corals, which together accumulate more carbonates, favoring reef bio-construction (Carricart-Ganivet, 2004). The bioconstruction occurs via the fixation of carbon generated by the primary producers, in particular the zooxanthellae that are found within the coral tissue (Done et al., 1996). Our results showed that $O$. annularis and $O$. faveolata constitute most of the live coral cover, and their massive colonies with sizes from decimetres to meters, increase the accretion of the reef structure, topographic complexity and the three-dimensionality of the reef habitats. In fact, Orbicella species complex has been one of the most dominant corals of the Caribbean (Goreau, 1959).

From the analysis of the coral structure assemblage and diversity, the reefs that presented the greatest biodiversity and bioconstruction were identified as: Yuyum, Boca Paila, and Punta Allen in the central zone, and Mahahual, El Placer and Xahuayxol in the southern zone. The reefs with an intermediate biodiversity and bio-construction correspond to Xcalak and Tampalam. In contrast, the reefs with the lowest biodiversity and poorest reef development are Punta Nizuc, Puerto Morelos and Punta Maroma in the northern zone. However, the results obtained for the bio-construction estimation should be taken with caution given that the lineal growth rates used do not entirely reflect the response of the corals with respect to the variation of the environmental variables. Nevertheless, they are considered to be a good approximation to this property of the functioning of the coral reef ecosystem.

The relationship among the abundance of $O$. annularis and O. faveolata, reef habitat area, live coral cover and topographic complexity was essential for determining the characteristics of the structure and diversity of the reefs of the nsMBRS. The results show that the studies at species and ensemble level enable to identify biodiversity and bio-construction patterns. This is important because by evaluating the benthic assemblages using coral ensembles, the global condition of the reefs is identified in a simple and fast manner. It is important because through the Caribbean, opportunistic coral species (Agaricia and Porites) are dominating and replacing the boulder corals as Orbicella spp., what produces substantial changes decreasing reef accretion and habitat complexity, and so affecting the ecosystem functioning (Alvarez-Filip et al., 2013).

Other factors exist that also influence the biodiversity and bioconstruction of the corals. For example coral recruitment is a sign that the reefs can maintain themselves (Ruíz-Zárate et al., 2003), although a specific correspondence between the structure of the assemblages of recruits, juveniles and adult corals has not been proved in the nsMBRS (Ruíz-Zárate et al., 2003; Ruíz-Zárate and Arias-González, 2004). This suggests that asexual reproduction is possibly maintaining the adult populations, particularly those of $O$. annularis and $O$. faveolata. Intra and interspecific biological interactions (e.g., competition) are important in structuring diversity, but these also act over small scales within the reef habitats.

The oceanographic and physiochemical characteristics of the seawater are also important for the development of corals. Although, these variables are not known in detail for the nsMBRS, it has been suggested recently that the distribution of Orbicella reefs is constrained in environments of high exposure (Chollett and Mumby, 2012). This pattern is likely to be driven in the nsMBRS by the frequent hurricanes and tropical storms, via the effects of storm surges and by the resuspension of sediments, variables that shape and structure the biodiversity and bio-construction of these reefs.

The effects of anthropogenic activities can change the transparency and concentration of nutrients of the seawater, favoring phase shifts in the reefs that may increase erosion, affect coral diversity and reduce live coral cover. These disturbances would have functional consequences on the coral reef ecosystems, given that the process of bio-construction would decrease, the reef structure would be eroded by physical and biological processes, and a loss of calcareous material to rubble, sand and slimy sediments would be produced. The persistence of the reefs requires the global growth rate of mass and volume to equal or exceed 
the losses by physical and biological erosion, hence persistence is a function of the benthic community structure and the vitality between the zooxanthellae and corals (Done et al., 1996).

Anthropogenic impacts modify and degrade the biodiversity of coral reefs. In the nsMBRS these impacts are a latent threat because of the effects of eutrophication, sedimentation and pollution (Bozec et al., 2008). The hotel infrastructure of the Cancun-Tulum tourist corridor is located in the northern zone, and the Mexican government recently approved the construction of another large tourist development in the southern zone that may have severe consequences in these fragile marine ecosystems. For this reason, the protection and conservation of the reef habitat area and the key species that maintain the resilience of the reefs, such as $O$. annularis y $O$. faveolata, which are long lived species (k-strategy) and spawning species that need to reach large sizes in order to reproduce (Harrison and Wallace, 1990; Sorokin, 1995), should be considered in the management plans of the nsMBRS. The high social-ecological value of Orbicella reefs rise their importance conservation planning (Mumby et al., 2008). The growth rates of these species are slow (Carricart-Ganivet, 2004) and often present high proportions of partially dead tissue due to susceptible to diseases and bleaching (Kramer, 2003). The decrease in their size and live cover reduces their fecundity and the viability of their populations. Therefore it is fundamental that the abundance of $O$. annularis y $O$. faveolata be maintained in order to conserve the bio-construction, live coral cover and biodiversity of the coral reefs of the nsMBRS. However, the influence of anthropogenic factors was not tested, since this was not the focus of this study, but it may be another important key driver, and should be considered for management and subsequent ecological studies.

\section{CONCLUSION}

The present study shows the importance of the function that $O$. annularis and O. faveolata present in shaping the structure and diversity of the coral assemblages of the nsMBRS at species, family and ensemble level. The sites with higher biodiversity present a greater contribution of $O$. annularis and $O$. faveolata and have a larger bio-construction. Similarly, the structure and diversity of their coral assemblages are related to higher reef habitat area, live coral cover and topographic complexity values. The sites with these characteristics were Mahahual, Yuyum, Xahuayxol and Punta Allen.

O. annularis and O. faveolata are related to the reef habitat area, which is the most important variable for their distribution and dominance. This is reflected in the geomorphological differences of the reefs of the nsMBRS. The reefs of the northern zone possess a small reef habitat area restricted to shallow areas where the contribution of $O$. annularis and $O$. faveolata is low; therefore the reefs are poorly developed. In contrast, the majority of the reefs of the central and southern zones present greater reef habitat area that include shallow and deep areas. This generates an increase in habitat heterogeneity and an increase in the contribution of de $O$. annularis and O. faveolata, which directly influence the formation of massive reef developments such as spur and groove systems. These conditions determine the structure and diversity of the coral assemblages. Where the proportion of $O$. annularis and $O$. faveolata is greater, more live coral cover and topographic complexity will exist, and together with the reef habitat area lead to greater coral species richness. The dominance of these two species also determines coral species composition.

$O$. annularis and $O$. faveolata species complex is key to maintain nsMBRS biodiversity because in addition to corals, other species associated with the reefs depend on the health and abundance of the corals. The current degradation of the reefs and their tendency to collapse implies urgent management and conservation plans are needed, that consider the protection and restoration of corals and their habitats in order to increase their natural resistance and resilience to anthropogenic and natural disturbances.

\section{ACKNOWLEDGMENTS}

This study was possible thanks to the funding by CONACYT, SEMARNAT-CONACYT and CINVESTAV. We acknowledge E. Nuñez-Lara, C. González-Salas, R. Hernández-Landa, M.A. RuízZárate, and G. Acosta-González for support during field trips, diving assistance and data stock. We thank the administration and personal of the Puerto Morelos, Sian Ka'an and Xcalak Marine Parks for their kind support. We would like to thank G. ÁvilaSoria for her useful comments to this manuscript and J.L. Cabrera for his help in designing the figures.

\section{SUPPLEMENTARY MATERIAL}

The Supplementary Material for this article can be found online at: http://www.frontiersin.org/journal/10.3389/fmars. 2015.00013/abstract

Supplementary Figure S1 | Accumulation curves of Shannon diversity representing the sampling effort at the studied eleven reef sites. All curves showed an asymptotic pattern what means the composition and abundance of coral species were correctly recorded during field work.

\section{REFERENCES}

Acosta-González, G., Rodríguez-Zaragoza, F. A., Hernández-Landa, R. C., and Arias-González, J. E. (2013). Spatiotemporal additive partitioning of fish diversity in a Caribbean coral reef undergoing shift transition. PLoS ONE 8:e65665. doi: 10.1371/journal.pone.0065665

Almany, G. R. (2004). Differential effects of habitat complexity, predators and competitors on abundance of juvenile and adult coral reef fishes. Oecologia 141, 105-113. doi: 10.1007/s00442-004-1617-0

Alva-Basurto, C., and Arias-González, J. E. (2014). Modelling the effects of climate change on a Caribbean coral reef food web. Ecol. Model. 289, 1-14. doi: 10.1016/j.ecolmodel.2014.06.014

Alvarez-Filip, L., Carricart-Ganivet, J. P., Horta-Puga, G., and Iglesias-Prieto, R. (2013). Shifts in coral-assemblage composition do not ensure persistence of reef functionality. Sci. Rep. 3:3486. doi: 10.1038/srep03486

Alvarez-Filip, L., Dulvy, N. K., Cõté I. M., Watkinson, A. R., and Gill, J. A. (2011). Coral identity underpins architectural complexity on Caribbean reefs. Ecol. Appl. 21, 2223-2231. doi: 10.1890/10-1563.1

Arias-González, J. E., Legendre, P., and Rodríguez-Zaragoza, F. A. (2008). Scaling up beta diversity on Caribbean coral reefs. J. Exp. Mar. Biol. Ecol. 366, 28-36. doi: 10.1016/j.jembe.2008.07.035

Arias-González, J. E., Núñez-Lara, E., González-Salas, C., and Galzin, R. (2004). Trophic models for investigation of fishing effect on coral reef ecosystems. Ecol. Model. 172, 197-212. doi: 10.1016/j.ecolmodel.2003.09.007

Arias-González, J. E., Núñez-Lara, E., Rodríguez-Zaragoza, F. A., and Legendre, P. (2011). Indicadores del paisaje arrecifal para la conservación de la biodiversidad de los arrecifes de coral del Caribe. Cienc. Mar. 37, 87-96.

Aronson, R. B., Edmunds, P. J., Precht, W. F., Swanson, D. W., and Levitan, D. R. (1994). Large scale, long-term monitoring of Caribbean coral reefs: 
simple, quick, inexpensive techniques. Atoll Res. Bull. 421, 1-19. doi: 10.5479/si.00775630.421.1

Bak, R. P. M., and Meesters, E. H (1997). "Coral diversity, populations and ecosystem functioning" in Proceedings of the 6th International Conference on Coelenterate Biology (Leiden: National Museum Natural History Press), 27-38.

Bellwood, D. R., and Hughes, T. P. (2001). Regional-scale assembly rules and biodiversity of coral reefs. Science 292, 1532-1534. doi: 10.1126/science.1058635

Bellwood, D. R., Hughes, T. P., Folke, C., and Nyström, M. (2004). Confronting the coral reef crisis. Nature 429, 827-833. doi: 10.1038/nature02691

Bozec, Y.-M., Acosta-González, G., Núñez-Lara, E., and Arias-González, J. E. (2008). Impacts of coastal development on ecosystem structure and function of Yucatan coral reefs, Mexico. Proc. 11th Inter. Coral Reef Symp. 2, 691-695.

Brown, B. E. (1997). "Disturbances to reefs in recent times," in Life and Dead of Coral Reefs, ed C. Birkeland (New York, NY: Hapman and Hall Press), 355-379.

Budd, A. F., Fukami, H., Smith,N. D., and Knowlton, N. (2012). Taxonomic classification of the reef coral family Mussidae (Cnidaria: Anthozoa: Scleractinia). Zool. J. Linn. Soc. 166, 465-529. doi: 10.1111/j.1096-3642.2012.00855.x

Carricart-Ganivet, J. P. (2004). Sea surface temperature and the growth of the West Atlantic reef-building coral Montastraea annularis. J. Exp. Mar. Biol. Ecol. 302, 249-260. doi: 10.1016/j.jembe.2003.10.015

Chollett, I., and Mumby, P. J. (2012). Predicting the distribution of Montastraea reefs using wave exposure. Coral Reefs 31, 493-503. doi: 10.1007/s00338-0110867-7

Clarke, K. R., and Warwick, R. M. (1994). Changes in Marine Communities: an Approach to Statistical Analysis and Interpretation. Plymouth: Bourne Press Ltd.

Cocito, S. (2004). Bioconstruction and biodiversity: their mutual influence. Sci. Mar. 68(Suppl.1), 137-144. doi: 10.3989/scimar.2004.68s1137

Colwell, R. K. (2005). Estimates: Statistical Estimation of Species Richness and Shared Species From Samples.Available online at: http://viceroy.eeb.uconn.edu/ estimates.

Done, T. J., Ogden, J. C., Wiebe, W. J., and Rosen, B. R. (1996). "Biodiversity and Ecosystem Function of Coral Reefs." in Funtional Roles of Biodiversity: A Global Perspective, eds H. A. Mooney, J. H. Cushman, E. Medina, O. E. Sala, and E. D. Schulze (John Wiley \& Sons LTD Press), 393-429.

Duran, D. (2006). Biological Responses of Two Caribbean reef-Building Corals to a Pier-Generated Irradiance Gradient. Tesis de Doctorado, Universidad de Puerto Rico, Campus Mayagüez.

Fauth, J. E., Bernardo, J., Camara, M., Resetarits, W. J., Van Buskirk, J., and McColling, S. A. (1996). Simplifying the jargon of community ecology: a conceptual approach. Am. Nat. 147, 282-286.

García-Urueña, R. P. (2004). Dinámica de Crecimiento de Tres Especies de Coral en Relación a Las Propiedades Ópticas del Agua. Tesis de Doctorado, Universidad de Puerto Rico, Campus Mayagüez.

Gardner, T. A., Cõté, M. I., Gill, J. A., Grant, A., and Watkinson, A. R. (2003). Long-term region-wide declines in Caribbean corals. Science 301, 958-960. doi: $10.1126 /$ science. 1086050

Goreau, T. F. (1959). The ecology of Jamaican coral reefs. I. Species composition and zonation. Ecology 40, 67-90. doi: 10.2307/1929924

Green, D. H., Edmunds, P. J., and Carpenter, R. C. (2008). Increasing relative abundance of Porites astreoides on Caribbean reefs mediated by an overall decline in coral cover. Mar. Ecol. Prog. Ser. 359, 1-10. doi: 10.3354/meps07454

Gutiérrez, D., García-Sáez, C., Lara, M., and Padilla, C. (1993). "Comparación de arrecifes coralinos: veracruz y quintana roo," in Biodiversidad Marina y Costera de México, eds S. I. Salazar-Vallejo and N. E. González (Chetumal: Conabio Press), 785-806.

Guzmán, H. M., Guevara, C. A., and Breedy, O. (2004). Distribution, diversity, and conservation of coral reefs and coral communities in the largest marine protected area of Pacific Panama (Coiba Island). Environ. Conser. 31, 111-121. doi: $10.1017 /$ S0376892904001250

Harrison, P. L., and Wallace, C. C. (1990). "Reproduction, dispersal, and recruitment of scleractinian corals," in Ecosystem of the Word: Corals Reefs, ed Z. Dubinsky (Amsterdam: Elsevier Science Publishing Company, Inc.), 133-208.

Healthy Reefs. (2012). Report card for the Mesoamerican reef: an evaluation of ecosystem health. Healthy Reefs Initiative. Available online at: www. healthyreefs.org

Hill, M. O. (1973). Diversity and evenness: a unifying notation and its consecuences. Ecology 54, 427-432. doi: 10.2307/1934352

Jackson, J. B. C., Kirby, M. X., Berger, W. H., Bjordal, K. A., Botsford, L. W., Bourque, B. J., et al. (2001). Historical overfishing and the recent collapse of coastal ecosystems. Science 293, 629-638. doi: 10.1126/science.1059199
Jones, G. P., McCormick, M. I., Srinivasan, M., and Eagle, J. V. (2004). Coral decline threatens biodiversity in marine reserves. Proc. Nat. Acad. Sci. U.S.A. 101, 8251-8253. doi: 10.1073/pnas.0401277101

Jordán-Dahlgren, E. (1993). Atlas de los Arrecifes Coralinos del Caribe Mexicano. Parte I. El Sistema Continental. Centro de Investigaciones de Quintana Roo.

Jordán-Dahlgren, E., and Rodríguez-Martínez, R. E. (2003). "The Atlantic coral reefs of Mexico," in Latin American Coral Reefs ed J. Cortés (Amsterdam: Elsevier Science B.V.), 131-158.

Kramer, P. A. (2003). Synthesis of coral reef health indicators for the western Atlantic: results of AGRRA program (1997-2000). Atoll Res. Bull. 406, 1-57. doi: 10.5479/si.00775630.496-3.1

Lang, J., and Chornesky, E. A. (1990). "Competition between scleractinian reef corals: a review of mechanisms and effects," in Ecosystem of the Word: Corals reefs, ed Z. Dubinsky (Amsterdam: Elsevier Science Publishing Company, Inc.), 209-252.

Legendre, P., and Gallagher, E. D. (2001). Ecologically meaningful transformations for ordination of species data. Oecologia 129, 271-280. doi: $10.1007 / \mathrm{s} 004420100716$

Legendre, P., and Legendre, L. (1998). Numerical Ecology, 2nd English Edn. Amsterdam: Elsevier Science BV.

Miller, M. W., Weil, E., and Szmant, A. M. (2000). Coral recruitment and juvenile mortality as structuring factors for reef benthic communities in Biscayne National Park, USA. Corals Reefs 19, 115-123. doi: 10.1007/s003380 000079

Mora, C. (2008). A clear human footprint in the coral reefs of the Caribbean. Proc. Biol. Sci. 275, 767-773. doi: 10.1098/rspb.2007.1472

Mumby, P. J., Broad, K., Brumbaugh, D. R., Dahlgren, C. P., Harborne, A. R., Hastings, A., et al. (2008). Coral reef habitats as surrogates of species, ecological functions, and ecosystem services. Conserv Biol 22, 941-951. doi: 10.1111/j.1523-1739.2008.00933.x

Núñez-Lara, E., Arias-González, J. E., and Legendre, P. (2005). Spatial patterns of Yucatan reef fish communities: testing models using a multi-scale survey design. J. Exp. Mar. Biol. Ecol. 324, 157-169. doi: 10.1016/j.jembe.2005. 04.011

Nzali, L. M., Jhonstone, R. W., and Mgaya, Y. D. (1998). Factores affecting scleractinian coral recruitment on nearshore reef in Tanzania. Ambio 27, 717-722.

Palumbi, S. R. (1997). Molecular biogeography of the Pacific. Coral Reefs 16, S47-S52. doi: 10.1007/s003380050241

Pandolfi, J. M., Bradbury, R. H., Sala, E., Hughes, T. P., Bjorndal, K. A., Cooke, R. G., et al. (2003). Global trajectories of the long-term decline of coral reef ecosystems. Science 301, 955-958. doi: 10.1126/science.1085706

Pearson, D. L. (1995). "Selecting indicator taxa for the quantitative assessment of biodiversity" in Biodiversity: Measurement and Estimation, ed D. L. Hawksworth (Oxford: The Royal Society-Chapman \& Hall Press), 75-80.

Reyes-Bonilla, H., Millet-Encalada, M., and Álvarez-Filip, L. (2014). Community structure of scleractinian corals outside protected areas in Cozumel Island, México. Atoll Bull. Res. 601, 1-13. doi: 10.5479/si.007756 30.601

Rodríguez-Zaragoza, F. A., and Arias-González, J. E. (2008). Additive partitioning of reef fish diversity across multiple spatial scales. Caribb. J. Sci. 44, 90-101.

Ruíz-Zárate, M. A., and Arias-González, J. E. (2004). Spatial study of juvenile corals in the Northern region of the Mesoamerican Barrier reef system (MBRS). Coral Reefs 23, 584-594. doi: 10.1007/s00338-004-0420-Z

Ruíz-Zárate, M. A., Hernández-Landa, R., González-Salas, C., Núñez-Lara, E., and Arias-González, J. E. (2003). Condition of coral reef ecosystems in centralsouthern Quintana Roo (Part 1: stony corals and algae). Atoll Bull. Res. 496, 318-337. doi: 10.5479/si.00775630.496-18.318

Sorokin, I. Y. (1995) Coral Reef Ecology, 2nd Edn. New york, NY: Springer Verlag. ter Braak, C. J. F., and Šmilauer, P. (2002). CANOCO Referente Manual and CanoDraw for windows user's guide: software for canonical community ordination (version 4.5). Microcomputer Power U.S.A. 500.

Tomascik, T., Van Woesik, R., and Mah, A. J. (1996). Rapid coral colonization of a recent lava flow following a volcanic eruption, Banda Islands, Indonesia. Coral Reefs 15, 169-175.

Veron, J. E. N. (1995). Corals and Space and Time: the Biogeography and Evolution of the Scleractinia. New York, NY: Cornell University Press.

Weidie, A. E. (1985). "Geology of the Yucatán platform," in Geology and Hidrogeology of the Yucatán and Quaternary Geology of Northeastern Yucatan 
Peninsula, eds A. E. Ward, A. E. Weidie and W. Back (New Orleans, LA: Geol. Soc.), $1-19$.

Yakob, L., and Mumby, P. J. (2011). Climate change induces demographic resistance to disease in novel coral assemblages. Proc. Natl. Acad. Sci. U.S.A. 108, 1967-1969. doi: 10.1073/pnas.1015443108

Conflict of Interest Statement: The authors declare that the research was conducted in the absence of any commercial or financial relationships that could be construed as a potential conflict of interest.

Received: 13 November 2014; paper pending published: 09 January 2015; accepted: 07 February 2015; published online: 03 March 2015.
Citation: Rodríguez-Zaragoza FA and Arias-González JE (2015) Coral biodiversity and bio-construction in the northern sector of the mesoamerican reef system. Front. Mar. Sci. 2:13. doi: 10.3389/fmars.2015.00013

This article was submitted to Coral Reef Research, a section of the journal Frontiers in Marine Science.

Copyright () 2015 Rodríguez-Zaragoza and Arias-González. This is an open-access article distributed under the terms of the Creative Commons Attribution License (CC BY). The use, distribution or reproduction in other forums is permitted, provided the original author(s) or licensor are credited and that the original publication in this journal is cited, in accordance with accepted academic practice. No use, distribution or reproduction is permitted which does not comply with these terms. 